\title{
Cinética de secagem das sementes da pitaya vermelha (Hylocereus polyrhizus)
}

\author{
Drying kinetic of red pitaya (Hylocereus polyrhizus) \\ Cinética de secado de semillas de pitaya roja (Hylocereus polyrhizus)
}

Karoline Thays Andrade Araújo ORCID: https://orcid.org/0000-0002-9356-3288 Universidade Federal de Campina Grande, Brasil E-mail: karoline_thays@ hotmail.com

Rossana Maria Feitosa de Figueirêdo ORCID: https://orcid.org/0000-0002-6187-5826 Universidade Federal de Campina Grande, Brasil E-mail: rossanamff@gmail.com

Alexandre José de Melo Queiroz ORCID: https://orcid.org/0000-0002-6880-5951 Universidade Federal de Campina Grande, Brasil E-mail: alexandrejmq@gmail.com

Renato Costa da Silva

ORCID: https://orcid.org/0000-0003-3172-4776

Universidade Federal de Campina Grande, Brasil E-mail: renatinocosta@gmail.com

Yaroslávia Ferreira Paiva

ORCID: https://orcid.org/0000-0002-2096-2122 Universidade Federal de Campina Grande, Brasil E-mail: yaroslaviapaiva@ gmail.com

Lumara Tatiely Santos Amadeu ORCID: https://orcid.org/0000-0001-7969-2959 Universidade Federal de Campina Grande, Brasil E-mail: lumaratatielyea@gmail.com

Carolaine Gomes dos Reis ORCID: https://orcid.org/0000-0003-1895-9116 Universidade Federal de Campina Grande, Brasil

E-mail: carolainetecalimentos@gmail.com

João Paulo de Lima Ferreira ORCID: https://orcid.org/0000-0003-1172-7259 Universidade Federal de Campina Grande, Brasil E-mail: joaop_1@hotmail.com

\begin{abstract}
Resumo
A pitaya vem despertando a atenção dos consumidores e fruticultores em diversas regiões do Brasil, especialmente devido à sua caraterística exótica. Após exploração da polpa do fruto é gerada grande quantidade de sementes que podem ser utilizadas para extração de óleo após secagem prévia. Assim, objetivou-se secar sementes de pitaya vermelha (Hylocereus polyrhizus) em secador convectivo nas temperaturas de 50,60 e $70{ }^{\circ} \mathrm{C}$ e velocidades do ar de desidratação de 0,55 e $0,75 \mathrm{~m} \mathrm{~s}^{-1}$, e ajustar diferentes modelos matemáticos aos dados experimentais. Observou-se que o aumento da temperatura e velocidade do ar de secagem promoveu redução nos tempos de desidratação, sendo que o processo ocorreu em período de taxa de redução de água decrescente, em todas as condições avaliadas. Dentre os modelos ajustados aos dados das cinéticas de secagem, o de Page foi selecionado como o mais adequado para representar o fenômeno investigado, apresentando coeficientes de determinação $\left(\mathrm{R}^{2}\right)$ superiores a 0,99 , desvios quadráticos médios (DMQ) inferiores a 0,030 e distribuição aleatória dos resíduos.
\end{abstract}

Palavras-chave: Cactácea; Desidratação; Modelagem matemática.

\begin{abstract}
The pitaya has been attracting the attention of consumers and fruit growers in different regions of Brazil, especially due to its exotic characteristic. After exploring the pulp of the fruit, a large amount of seeds is generated that can be used for oil extraction after previous drying. Thus, the objective was to dry seeds of red pitaya (Hylocereus polyrhizus) in a convective dryer at temperatures of 50,60 and $70{ }^{\circ} \mathrm{C}$ and dehydration air speeds of 0.55 and $0.75 \mathrm{~m} \mathrm{~s}$ 1 , and to adjust different models to experimental data. It was observed that the increase in the temperature and speed of the drying air promoted a reduction in dehydration times, and the process occurred in a period of decreasing water reduction rate, in all conditions evaluated. Among the models adjusted to the drying kinetics data, Page was selected
\end{abstract}


as the most suitable to represent the investigated phenomenon, presenting coefficients of determination (R2) above 0.99 , mean square deviations (DMQ) below 0.030 and distribution random waste.

Keywords: Cactaceae; Dehydration; Mathematical modeling.

\section{Resumen}

La pitaya ha estado atrayendo la atención de consumidores y fruticultores en diferentes regiones de Brasil, especialmente por su característica exótica. Luego de explorar la pulpa del fruto, se genera una gran cantidad de semillas que pueden ser utilizadas para la extracción de aceite luego de un secado previo. Así, el objetivo fue secar semillas de pitaya roja (Hylocereus polyrhizus) en un secador convectivo a temperaturas de 50,60 y $70{ }^{\circ} \mathrm{C}$ y velocidades del aire de deshidratación de 0.55 y $0.75 \mathrm{~m} \mathrm{~s}-1$, y ajustar diferentes modelos a datos experimentales. Se observó que el aumento de la temperatura y la velocidad del aire de secado promovió una reducción de los tiempos de deshidratación, y el proceso ocurrió en un período de disminución de la tasa de reducción de agua, en todas las condiciones evaluadas. Entre los modelos ajustados a los datos de la cinética de secado, Page fue seleccionado como el más adecuado para representar el fenómeno investigado, presentando coeficientes de determinación (R2) por encima de 0,99, desviaciones cuadradas medias (DMQ) por debajo de 0,030 y distribución aleatoria de residuos.

Palabras clave: Cactaceae; Deshidración; Modelo matematico.

\section{Introdução}

Na região Nordeste do Brasil, as cactáceas encontram condições edafoclimáticas propícias para o seu plantio e consequente exploração. Dentre as cactáceas, a pitaya vem sendo difundida no Brasil devido, principalmente, a sua aparência exótica e alto valor comercial. A espécie é originária da América e cultivada em todo o mundo, sendo a Colômbia e o México os principais produtores de pitaya. No Brasil encontram-se plantios comerciais principalmente nos Estados de São Paulo, Mato Grosso, Goiás, Minas Gerais, Espírito Santo, Bahia, Ceará e Pernambuco.

É comum serem encontradas no Brasil espécies de pitaya dos gêneros Selenicereus e Hylocereus, em estádio nativo, no Cerrado e na Caatinga (Lima et al., 2014). Entretanto, dentre as várias espécies de pitayas, destacam-se a Hylocereus polyrhizus (pitaya vermelha de polpa vermelha) e a Hylocereus undatus (pitaya vermelha de polpa branca), que estão entre as mais produzidas e comercializadas, uma vez que apresentam polpa com sabor agradável e de grande aceitação sensorial pelos consumidores (Abreu et al., 2012).

A polpa (mesocarpo) é a parte comestível do fruto, formada por massa de textura mucilaginosa, com sementes pequenas e macias, distribuídas homogeneamente, representando de 60 a $80 \%$ do peso dos frutos maduros. O rendimento de polpa representa em torno de $55 \%$ do fruto, embora maiores variações possam ser encontradas entre as diferentes espécies (Lima et al., 2013). Após a exploração comercial da polpa, é gerada grande quantidade de resíduos constituídos pelas cascas e sementes, que podem ser melhor aproveitadas para extração de betalainas e óleo, respectivamente, com vasta aplicação agroindustrial.

De acordo com Liaotrakoon et al. (2013) as sementes, que medem cerca de 2-3 mm de diâmetro e correspondem a aproximadamente $8 \%$ do peso do fruto, contém conteúdo de óleo variando entre 32 e $34 \%$, sendo considerado como uma fonte potencial de ácidos graxos essenciais e tocoferóis, com uma boa resistência à oxidação. Ariffin et al. (2009) ainda destacaram que o óleo das sementes de pitaya contém cerca de $51 \%$ de ácidos graxos essenciais, sendo 50\% de ácido linoleico e $1 \%$ de ácido linolênico, podendo ser utilizado como uma nova fonte de óleo essencial devido ao elevado nível de lipídeos funcionais.

Em virtude da elevada perecibilidade das sementes de pitaya, torna-se necessário reduzir o seu conteúdo de água a níveis seguros que garantam a sua qualidade, constituindo-se em procedimento importante para a extração do óleo (Mendonça et al., 2015). Dentre os métodos que podem ser empregados, a secagem é mais utilizado, uma vez que controla o a atividade biológica (Santos et al., 2013a) através da redução da atividade de água, evitando desse modo o desenvolvimento de microrganismos e retardando as reações bioquímicas, o que aumenta a sua armazenabilidade (Santos et al., 2014). Muitos estudos foram conduzidos com o objetivo de investigar a secagem de sementes e grãos (Carlesso et al., 2007; Corrêa et al., 2007; Roberts et al., 2008; Diógenes et al., 2013; Santos et al., 2013b; Mendonça et al., 2015), porém não foram encontrados relatos acerca da 
desidratação de sementes de pitaya, sendo a maior parte das pesquisas relacionadas com o cultivo e a qualidade dos frutos, fato este que motivou a realização desta pesquisa.

Ante o exposto, o objetivo desse trabalho foi secar sementes de pitaya (Hylocereus polyrhizus (Haw) Britton \& Rose) em diferentes temperaturas $\left(50,60\right.$ e $\left.70{ }^{\circ} \mathrm{C}\right)$ e velocidades do ar de desidratação $\left(0,55\right.$ e $\left.0,75 \mathrm{~m} \mathrm{~s}^{-1}\right)$ e ajustar diferentes modelos matemáticos aos dados experimentais das cinéticas de secagem.

\section{Metodologia}

Foram utilizadas pitayas com casca e polpa vermelhas (Hylocereus polyrhizus (Haw) Britton \& Rose), em estádios de maturação maduras, cultivadas em Limoeiro do Norte, CE. As frutas foram transportadas adequadamente ao laboratório, onde foram selecionadas quanto a ausência de danos físicos, lavadas em água corrente para remoção de sujidades aderidas a casca, sanitizadas em solução clorada a 50 ppm de cloro ativo por 15 min e enxaguadas em água de boa qualidade. Na sequência, as pitayas foram submetidas a cortes diagonais, sendo a polpa contendo as sementes removida da casca manualmente com uso de colheres de aço inoxidável.

A separação das sementes da polpa foi realizada em prensa hidráulica, modelo AISI 304, da marca Macanuda, operando com uma força de 6 t. Entretanto, devido à textura mucilaginosa da polpa, as sementes ainda permaneceram com resíduos da mesma, sendo estes foram removidos através da lavagem das sementes em água corrente. Em seguida, as sementes foram espalhadas em peneiras planas onde permaneceram por 2 horas para drenagem da água de lavagem. Antes do início das secagens, determinou-se o teor de água inicial das amostras pelo método de estufa a $105 \pm 2^{\circ} \mathrm{C}$ até peso constante.

As secagens em camada fina foram realizadas em triplicata, com cada experimento constituído por cerca de $10 \mathrm{~g}$ de sementes espalhadas uniformemente em cestas montadas com arames de aço inoxidável com malha de 1 mícron, em secador convectivo nas temperaturas de 50, 60 e $70{ }^{\circ} \mathrm{C}$ e velocidade do ar de desidratação de 0,55 e $0,75 \mathrm{~m} \mathrm{~s}^{-1}$. Em tempos regulares as amostras foram pesadas até massa constante, sendo então determinada a massa seca em estufa a $105{ }^{\circ} \mathrm{C}$. Com os dados experimentais das cinéticas de secagem foram calculadas as razões do teor de água das amostras, de acordo com a Equação (1).

$$
\mathrm{RX}=\frac{\mathrm{X}-\mathrm{x}_{\mathrm{eq}}}{\mathrm{X}_{0}-\mathrm{X}_{\mathrm{eq}}}
$$

Em que: $\mathrm{X}$ - teor de água do produto (b.s.); $\mathrm{X}_{0}$ - teor de água inicial (b.s.); $\mathrm{X}_{\mathrm{eq}}$ - teor de água de equilíbrio (b.s.).

Os modelos matemáticos descritos na Tabela 1, frequentemente utilizados em estudos de desidratação de produtos agrícolas, foram ajustados às curvas de razão do teor de água em função do tempo de secagem, através de regressão não linear, pelo método Quasi-Newton, empregando-se o programa computacional Statistica 7.0. 
Tabela 1. Modelos matemáticos ajustados às curvas de cinética de secagem das sementes de pitaya vermelha.

\begin{tabular}{cccc}
\hline Designação do modelo & Equação & Referência \\
\hline Exponencial de Dois Termos & $\mathrm{RX}=\mathrm{a} \cdot \exp (-\mathrm{k} . \mathrm{t})+(1-\mathrm{a}) \cdot \exp (-\mathrm{k} . \mathrm{a} . \mathrm{t})$ & Ferreira et al. $(2012)$ & 2 \\
Henderson \& Pabis & $\mathrm{RX}=\mathrm{a} \cdot \exp (-\mathrm{k} . \mathrm{t})$ & Santos et al. $(2015)$ & 3 \\
Logarítmico & $\mathrm{RX}=\mathrm{a} \cdot \exp (-\mathrm{k} . \mathrm{t})+\mathrm{c}$ & Diógenes et al. $(2013)$ & 4 \\
Page & $\mathrm{RX}=\exp \left(-\mathrm{k} . \mathrm{t}^{\mathrm{n}}\right)$ & Galdino et al. $(2016)$ & 5 \\
Newton & $\mathrm{RX}=\exp (-\mathrm{k} . \mathrm{t})$ & Sousa et al. $(2011)$ & 6 \\
\hline
\end{tabular}

Em que: RX - razão do teor de água(adimensional); a, c, k, n - constantes dos modelos; $\mathrm{t}$ - tempo (min). Fonte: Autores.

$\mathrm{Na}$ avaliação do ajuste dos modelos aos dados experimentais foi utilizada como critério de seleção a análise do coeficiente de determinação $\left(\mathrm{R}^{2}\right)$, a distribuição dos resíduos e o desvio quadrático médio (DQM), conforme Equação 6.

$$
\mathrm{DQM}=\left[\frac{1}{\mathrm{n}} \sum_{\mathrm{i}=1}^{\mathrm{n}}\left(\mathrm{RX}_{\text {pred,i }}-\mathrm{RX}_{\text {exp }, \mathrm{i}}\right)^{2}\right]^{\frac{1}{2}}
$$

Em que: $\mathrm{DQM}$ - desvio quadrático médio; $\mathrm{RX}_{\text {pred }}$ - razão de água predito pelo modelo; $\mathrm{RX}_{\exp }$ - razão de água experimental; $\mathrm{n}$ - número de observações.

A partir dos dados de teor de água das sementes de pitaya vermelha e dos tempos de secagem, foram calculadas as taxas de secagem das amostras (Equação 8).

$$
\mathrm{TX}=\frac{\mathrm{X}_{\mathrm{t}+\mathrm{dt}}-\mathrm{X}_{\mathrm{t}}}{\mathrm{dt}}
$$

Em que: TX - taxa de secagem, $\mathrm{kg} \mathrm{kg} \cdot \mathrm{min}^{-1} ; \mathrm{X}_{\mathrm{t}+\mathrm{dt}}$ - teor de água em $\mathrm{t}+\mathrm{dt}$, (kg de água/kg de matéria seca); $\mathrm{X}_{\mathrm{t}}$ - teor de água no tempo t, (kg de água/kg de matéria seca); $\mathrm{t}$ - tempo de secagem, min.

\section{Resultados e Discussão}

Tem-se na Figura 1 as curvas de secagem das sementes de pitaya vermelha nas temperaturas de 50,60 e $70{ }^{\circ} \mathrm{C}$ e velocidades do ar de desidratação de 0,55 e $0,75 \mathrm{~m} \mathrm{~s}^{-1}$. O conteúdo de água inicial, que variou de 74-84\% b.u., foi reduzido rapidamente no início do processo de secagem, atingindo teores de água de equilíbrio de 9,17; 5,82, e 5,61\% b.u. (sementes desidratadas na velocidade de $0,55 \mathrm{~m} \mathrm{~s}^{-1}$ ) e 8,$15 ; 4,71$ e 3,98\% b.u. (sementes desidratadas na velocidade de $0,75 \mathrm{~m} \mathrm{~s}^{-1}$ ) para as temperaturas de 50,60 e $70{ }^{\circ} \mathrm{C}$, respectivamente. Os tempos necessários para a condução das secagens foram de 180,120 e 80 min para o fluxo de ar de 0,55 $\mathrm{m} \mathrm{s}^{-1}$ e de 80, 60 e 40 min na velocidade do ar de desidratação de $0,75 \mathrm{~m} \mathrm{~s}^{-1}$, nas respectivas temperaturas de 50, 70 e $70{ }^{\circ} \mathrm{C}$. Percebeu-se que o aumento da temperatura ocasionou redução dos tempos de secagem, fenômeno frequentemente relatado em estudos de desidratação de sementes, grãos e outros produtos agrícolas (Roberts et al., 2008; TaheriGaravand et al., 2011; Chayjan et al., 2012; Ferreira et al., 2012; Deamici et al., 2016; Galdino et al., 2016; Guimarães et al., 2017). Sousa et al. (2011) relataram que o aumento da temperatura do ar de secagem faz com que haja uma maior taxa de remoção de água da semente devido a um maior gradiente de umidade entre a semente e o ar, decrescendo o tempo necessário 
para reduzir o teor de água até o valor desejado. Assim, é de se esperar que em temperaturas mais elevadas as sementes de pitaya demandassem menor tempo para atingirem o equilíbrio higroscópico.

Figura 1. Curvas de secagem das sementes de pitaya vermelha nas temperaturas de 50,60 e $70{ }^{\circ} \mathrm{C}$ e velocidades do ar de desidratação de 0,55 (A) e $0,75 \mathrm{~m} \mathrm{~s}^{-1}$ (B).

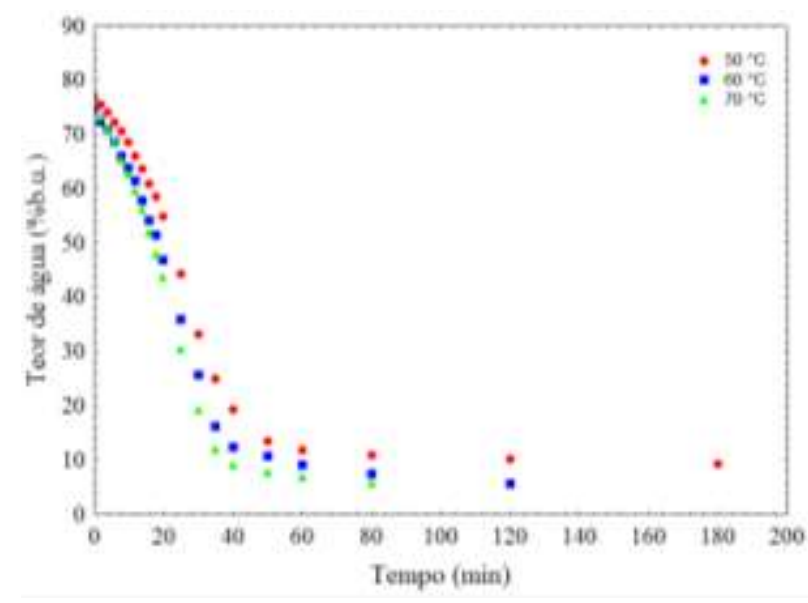

A

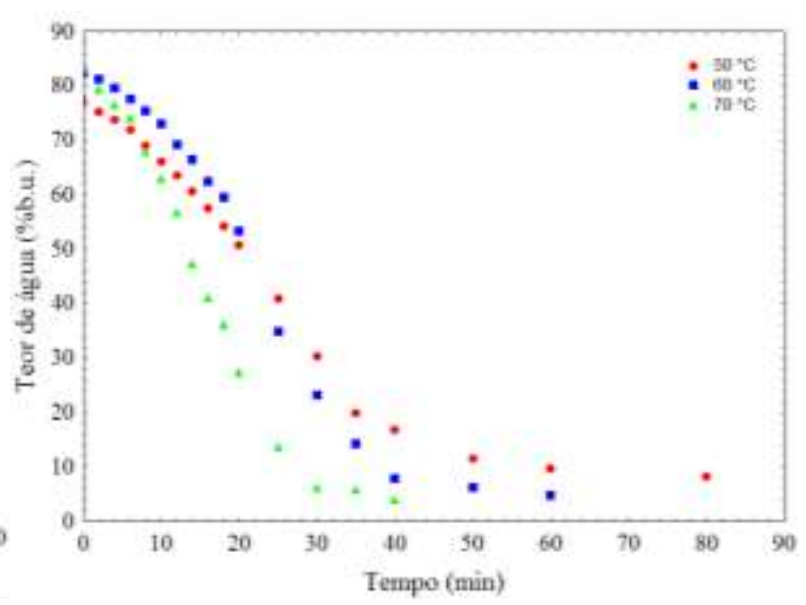

B

Fonte: Autores.

Para uma mesma temperatura de secagem, o incremento de $0,20 \mathrm{~m} \mathrm{~s}^{-1}$ de fluxo de ar resultou em decréscimo em torno de 50\% nos tempos de desidratação (Figura 1), o que já era esperado, haja vista que a literatura aponta a o fluxo do ar como uma das variáveis que pode afetar a desidratação de produtos agrícolas (Taheri-Garavand, 2011). Esse ccomportamento também foi evidenciado por Borges et al. (2010) e Chayjan et al. (2012) ao investigarem a secagem de banana e melão, respectivamente. Carlesso et al. (2007) verificaram, ao estudarem a secagem em camada fina de sementes de maracujá amarelo, que o efeito do aumento da temperatura na redução do tempo de secagem foi acentuado pelo aumento da velocidade do ar, corroborando os resultados deste estudo. Também deve ser considerado que o tamanho relativamente pequeno das sementes (Liaotrakoon et al., 2013) pode ter favorecido o processo de difusão de água do interior da amostra para a parte superficial, possivelmente devido a menores resistências estruturais, onde a água migrada para a superfície foi evaporada com maior velocidade pela ação conjunta da temperatura com o maior fluxo de ar.

Estão dispostas na Figura 2 as taxas de secagem das sementes de pitaya vermelha nas temperaturas de 50,60 e $70{ }^{\circ} \mathrm{Ce}$ velocidade de ar de desidratação de 0,55 e $0,75 \mathrm{~m} \mathrm{~s}^{-1}$. Não se observou nenhum período de secagem a taxa constante, sendo as desidratações processadas em período de taxa de remoção de água decrescente em qualquer condição de secagem, estando em acordo com as observações de Santos et al. (2013b), Diógenes et al. (2013) e Martins et al. (2014) em grãos residuais de urucum, grãos de abóbora e cascas de mulungu, respectivamente. Deamici et al. (2016) afirmaram que quando o processo de secagem ocorre sem o período de taxa constante, a difusão se torna o mecanismo físico dominante que impulsiona a transferência de massa na forma de água do material para o ar de secagem. Esse comportamento foi devido, provavelmente, a composição química das sementes de pitaya, que apresentam elevado conteúdo de óleo (Liaotrakoon et al., 2013). 
Figura 2. Taxas de secagem das sementes de pitaya vermelha nas temperaturas de 50, 60 e $70{ }^{\circ} \mathrm{C}$ e velocidade de ar de desidratação de 0,55 (A) e $0,75 \mathrm{~m} \mathrm{~s}^{-1}$ (B).



A

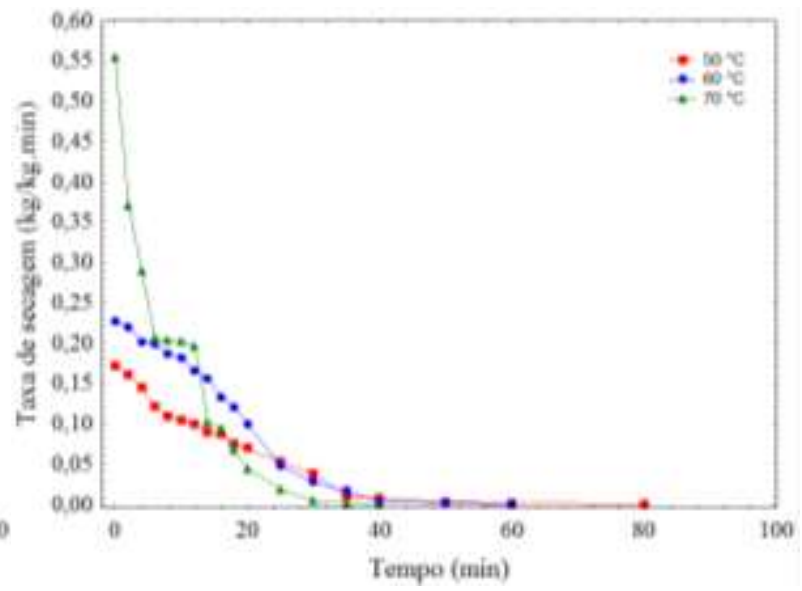

B

Fonte: Autores.

As maiores taxas de secagem foram verificadas no início do processo, em todas as condições de desidratação, sendo reduzidas gradativamente com o prosseguimento do experimento, sendo este comportamento reportado em produtos como pimenta (Rabha et al., 2017) e grãos residuais de urucum (Santos et al., 2014). As curvas apresentaram uma parte linear de declive significativo no início da secagem, o que correspondeu a uma rápida perda de água livre (Massamba et al., 2012). Após isso, houve inflexão das curvas uma vez que o solvente aquoso encontrava-se fortemente ligada a matéria seca, o que reduziu consideravelmente a velocidade de remoção de água. Constatou-se ainda a existência de dependência da taxa de secagem com a temperatura e velocidade do ar, sendo encontradas taxas com magnitudes de 0,135; 0,164 e 0,233 kg kg.min ${ }^{-1}$ para as sementes desidratadas na velocidade de $0,55 \mathrm{~m} \mathrm{~s}^{-1}$ e 0,$172 ; 0,227$ e $0,554 \mathrm{~kg} \mathrm{~kg} \cdot \mathrm{min}^{-1}$ para as secagens na velocidade de $0,75 \mathrm{~m} \mathrm{~s}^{-1}$, ambas nas temperaturas de 50, 60 e $70{ }^{\circ} \mathrm{C}$, respectivamente (Figura 2). Assim, em uma mesma temperatura, o aumento do fluxo de ar em $0,2 \mathrm{~m} \mathrm{~s}^{-1}$ promoveu incrementos da taxa de secagem, sendo que a $70{ }^{\circ} \mathrm{C}$ e $0,75 \mathrm{~m} \mathrm{~s}^{-1}$, a velocidade de secagem foi cerca de $138 \%$ mais rápida quando comparada com a condição de $70{ }^{\circ} \mathrm{C}$ e $0,55 \mathrm{~m} \mathrm{~s}^{-1}$, o que justifica a considerável redução do tempo de secagem (Figura 1).

Encontram-se nas Tabelas 2 e 3 os parâmetros dos diferentes modelos matemáticos ajustados aos dados experimentais da cinética de secagem das sementes de pitaya vermelha nas temperaturas de 50,60 e $70{ }^{\circ} \mathrm{C}$ e velocidades do ar de desidratação de 0,55 e $0,75 \mathrm{~m} \mathrm{~s}^{-1}$, respetivamente, assim como os coeficientes de determinação $\left(\mathrm{R}^{2}\right)$, os desvios quadráticos médios (DQM) e a distribuição dos resíduos. Observou-se que todos os modelos apresentaram valores de $\mathrm{R}^{2}$ superiores a 0,98 , indicando uma representação satisfatória do fenômeno estudado (Sousa et al., 2011). Resultados similares foram reportados por Roberts et al. (2008) que, ao secarem sementes de uvas em camada, evidenciaram dados de $\mathrm{R}^{2}$ elevados, superior a 0,96, para os modelos matemáticos de Page e Henderson \& Pabis ajustados aos dados experimentais, e por Diógenes et al. (2013) que encontraram valores de $\mathrm{R}^{2}$ maiores que 0,96 ao ajustarem os modelos matemáticos de Exponencial de Dois Termos, Henderson \& Pabis, Logarítmico e Page aos dados da cinética de secagem de grãos de abóbora inteiros e sem tegumento. 
Tabela 2. Parâmetros obtidos, coeficientes de determinação $\left(R^{2}\right)$, desvios quadráticos médios (DQM) e distribuição dos resíduos (DR) dos modelos matemáticos ajustados às curvas de secagem de sementes de pitaya vermelha em diferentes temperaturas e velocidade do ar de $0,55 \mathrm{~m} \mathrm{~s}^{-1}$.

\begin{tabular}{|c|c|c|c|c|c|c|c|c|}
\hline \multirow{2}{*}{ Modelo } & \multirow{2}{*}{$\begin{array}{c}\text { Temp. } \\
\left({ }^{\circ} \mathrm{C}\right)\end{array}$} & \multicolumn{4}{|c|}{ Parâmetros } & \multirow{2}{*}{$\mathrm{R}^{2}$} & \multirow{2}{*}{ DQM } & \multirow{2}{*}{ DR } \\
\hline & & $\mathrm{a}$ & $\mathrm{c}$ & $\mathrm{k}$ & $\mathrm{n}$ & & & \\
\hline \multirow{3}{*}{1} & 50 & 0,9999 & - & 0,0536 & - & 0,9915 & 0,0439 & $\mathrm{~T}$ \\
\hline & 60 & 1,7595 & - & 0,0858 & - & 0,9984 & 0,0182 & $\mathrm{~T}$ \\
\hline & 70 & 1,6353 & - & 0,0940 & - & 0,9980 & 0,0199 & $\mathrm{~T}$ \\
\hline \multirow{3}{*}{2} & 50 & 1,0191 & - & 0,0576 & - & 0,9936 & 0,0382 & $\mathrm{~T}$ \\
\hline & 60 & 1,0416 & - & 0,0637 & - & 0,9948 & 0,0332 & $\mathrm{~T}$ \\
\hline & 70 & 1,0599 & - & 0,0741 & - & 0,9960 & 0,0279 & $\mathrm{~T}$ \\
\hline \multirow{3}{*}{3} & 50 & 1,0476 & $-0,0348$ & 0,0536 & - & 0,9947 & 0,0347 & $\mathrm{~T}$ \\
\hline & 60 & 1,0678 & $-0,0347$ & 0,0591 & - & 0,9959 & 0,0295 & $\mathrm{~T}$ \\
\hline & 70 & 1,0870 & $-0,0393$ & 0,0676 & - & 0,9974 & 0,0225 & A \\
\hline \multirow{3}{*}{4} & 50 & - & - & 0,0221 & 1,1378 & 0,9988 & 0,0165 & A \\
\hline & 60 & - & - & 0,0318 & 1,2339 & 0,9985 & 0,0180 & A \\
\hline & 70 & - & - & 0,0502 & 1,3114 & 0,9978 & 0,0210 & A \\
\hline \multirow{3}{*}{5} & 50 & - & - & 0,0536 & - & 0,9915 & 0,0439 & $\mathrm{~T}$ \\
\hline & 60 & - & - & 0,0607 & - & 0,9937 & 0,0363 & $\mathrm{~T}$ \\
\hline & 70 & - & - & 0,0725 & - & 0,9958 & 0,0287 & $\mathrm{~T}$ \\
\hline
\end{tabular}

A - Aleatória; T - tendencioso. Fonte: Autores.

Tabela 3. Parâmetros obtidos, coeficientes de determinação $\left(\mathrm{R}^{2}\right)$, desvios quadráticos médios (DQM) e distribuição dos resíduos (DR) dos modelos matemáticos ajustados às curvas de secagem de sementes de pitaya vermelha em diferentes temperaturas e velocidade do ar de $0,75 \mathrm{~m} \mathrm{~s}^{-1}$.

\begin{tabular}{|c|c|c|c|c|c|c|c|c|}
\hline \multirow{2}{*}{ Modelo } & \multirow{2}{*}{$\begin{array}{c}\text { Temp. } \\
\left({ }^{\circ} \mathrm{C}\right)\end{array}$} & \multicolumn{4}{|c|}{ Parâmetros } & \multirow{2}{*}{$\mathrm{R}^{2}$} & \multirow{2}{*}{ DQM } & \multirow{2}{*}{ DR } \\
\hline & & $\mathrm{a}$ & $\mathrm{c}$ & $\mathrm{k}$ & $\mathrm{n}$ & & & \\
\hline \multirow{3}{*}{1} & 50 & 1,0000 & - & 0,0662 & - & 0,9879 & 0,0518 & A \\
\hline & 60 & 1,6229 & - & 0,0870 & - & 0,9977 & 0,0208 & $\mathrm{~T}$ \\
\hline & 70 & 1,7697 & - & 0,1446 & - & 0,9991 & 0,0137 & A \\
\hline \multirow{3}{*}{2} & 50 & 1,0153 & - & 0,0645 & - & 0,9955 & 0,0306 & $\mathrm{~T}$ \\
\hline & 60 & 1,0481 & - & 0,0718 & - & 0,9914 & 0,0436 & $\mathrm{~T}$ \\
\hline & 70 & 1,0763 & - & 0,1156 & - & 0,9959 & 0,0277 & A \\
\hline \multirow{3}{*}{3} & 50 & 1,0437 & $-0,0502$ & 0,0579 & - & 0,9972 & 0,0241 & A \\
\hline & 60 & 1,0854 & $-0,0828$ & 0,0606 & - & 0,9951 & 0,0330 & $\mathrm{~T}$ \\
\hline & 70 & 1,1394 & $-0,0406$ & 0,1043 & - & 0,9974 & 0,0222 & A \\
\hline \multirow{3}{*}{4} & 50 & - & - & 0,0243 & 1,1288 & 0,9990 & 0,0149 & A \\
\hline & 60 & - & - & 0,0322 & 1,2324 & 0,9992 & 0,0132 & A \\
\hline & 70 & - & - & 0,0834 & 1,3715 & 0,9974 & 0,0219 & A \\
\hline \multirow{3}{*}{5} & 50 & - & - & 0,0610 & - & 0,9941 & 0,0352 & $\mathrm{~T}$ \\
\hline & 60 & - & - & 0,0661 & - & 0,9879 & 0,0518 & $\mathrm{~T}$ \\
\hline & 70 & - & - & 0,1138 & - & 0,9957 & 0,0282 & A \\
\hline
\end{tabular}


Apesar dos elevados $\mathrm{R}^{2}$, estes não podem ser considerados como o único critério de avaliação e seleção de modelos não lineares. Por isso também foram analisados o DQM e a distribuição dos resíduos. Percebeu-se que o modelo de Page foi aquele a apresentou os valores de DQM mais baixos, na maioria das condições de secagem, indicando boa qualidade do ajuste da equação em relação aos dados experimentais (SANTOS et al., 2015), corroborando os dados de secagem de outros produtos agrícolas (Guimarães et al., 2017; Galdino et al., 2016; Santos et al., 2014; Diógenes et al., 2013). Em relação à distribuição dos reedíduos, o modelo de Page foi o único a apresentar distribuição aleatória em todas as condições de secagem (Tabelas 2 e 3), o que evidencia que este modelo matemático foi o mais adequado para representar a desidratação de sementes de pitaya vermelha, nas condições experimentais estudadas deste trabalho. De acordo com Santos et al. (2013a), uma equação é classificada como aleatória se os seus resíduos não formarem figuras definidas, enquanto que se a mesma apresentar resíduos com distribuição em forma de figuras geométricas, a distribuição é tendenciosa (Mendonça et al., 2015).

A constante de secagem ' $\mathrm{k}$ ' de todos os modelos matemáticos ajustados aos dados experimentais da cinética de secagem das sementes de pitaya vermelha aumentou a incrementos de temperatura, o que segundo Corrêa et al. (2007) representa o efeito das condições externas de secagem. Assim, em condições de temperatura mais elevadas, houve maior difusão de água, reduzindo dessa forma os tempos de secagem, em virtude das maiores taxas de secagem (Mandala et al., 2005). Para uma mesma temperatura de desidratação, o parâmetro ' $\mathrm{k}$ ' mostrou-se mais elevado nas secagens com velocidade do ar de $0,75 \mathrm{~m} \mathrm{~s}^{-1}$, apresentando-se em acordo com os tempos de secagem mais baixos em comparação ao fluxo de 0,55 $\mathrm{m} \mathrm{s}^{-1}$ (Figura 1). Comportamento semelhante foi verificado por Diógenes et al. (2013), Santos et al. (2013b) e Roberts et al. (2008) ao estudarem a secagem de grãos de abóbora, grãos residuais de urucum e sementes de uva, respectivamente.

Notou-se que as constantes de secagem 'a' dos modelos de Henderson \& Pabis e Logarítmico e o parâmetro 'n' da equação de Page foram elevadas à medida que a temperatura de secagem era ampliada, o que refletem a extensão da resistência interna do produto à secagem, nas condições externas deste trabalho (Corrêa et al., 2007). Ferreira et al. (2012) também relataram, ao estudarem a secagem de bagaço de uva fermentado, aumento na magnitude da constante 'a' dos modelos de Henderson e Pabis e Logarítmico ajustados aos dados experimentais. No estudo de Galdino et al. (2016) foi observado que o parâmetro 'n' no modelo de Page sofreu incrementos na secagem de polpa de atemóia com a elevação da temperatura de desidratação de 60 para $80^{\circ} \mathrm{C}$, estando em acordo com o comportamento das sementes de pitaya.

Na Figura 3 encontram-se os dados experimentais da cinética de secagem das sementes de pitaya vermelha, nas temperaturas de 50,60 e $70{ }^{\circ} \mathrm{C}$ e velocidades do ar de 0,55 e $0,75 \mathrm{~m} \mathrm{~s}^{-1}$, expressos através da razão do teor de água (adimensional) em função do tempo de secagem (min), ajustadas pelo modelo de Page, considerado como o que melhor se ajustou aos dados das secagens. Observou-se uma proximidade das curvas preditas aos dados experimentais, estando em acordo com os valores de $\mathrm{R}^{2}$, DQM e a distribuição dos resíduos. 
Figura 3. Modelo de Page ajustado aos dados experimentais de cinética de secagem de sementes de pitaya vermelha nas temperaturas de 50, 60 e $70{ }^{\circ} \mathrm{C}$ e velocidades do ar de desidratação de 0,55 (A) e $0,75 \mathrm{~m} \mathrm{~s}^{-1}$ (B).

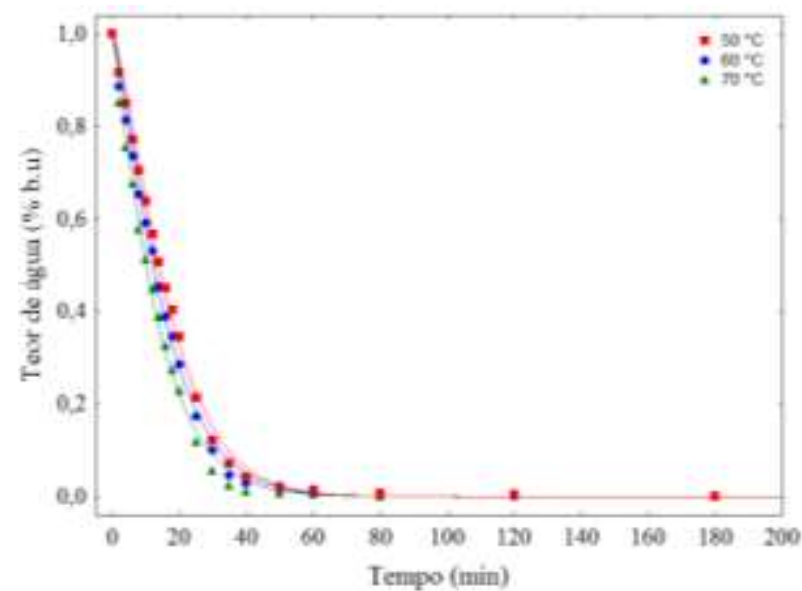

A

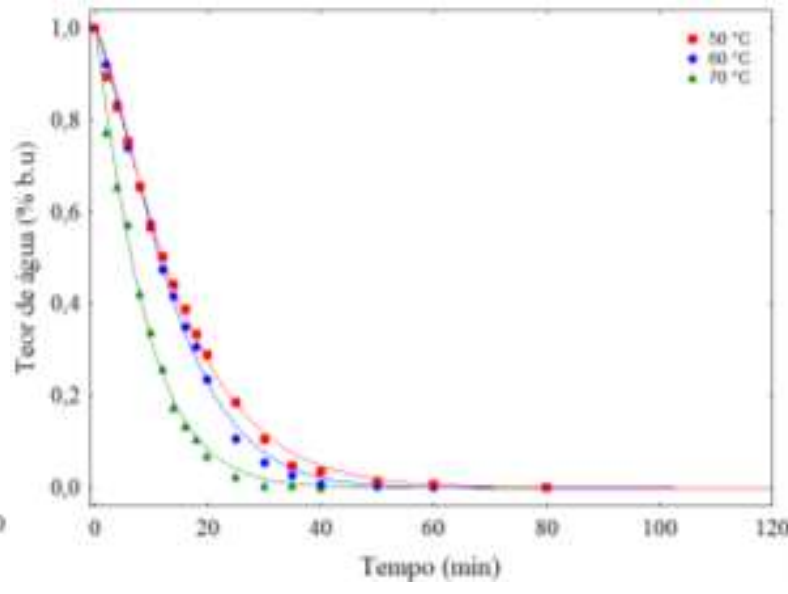

B

Fonte: Autores.

\section{Conclusão}

Há redução nos tempos de secagem das sementes de pitaya vermelha com o aumento da temperatura e da velocidade do ar de desidratação.

As cinéticas de secagem das sementes de pitaya apresentam apenas o período de taxa de remoção de água com comportamento decrescente. As magnitudes das taxas de secagens são maiores no início do processo e nas temperaturas mais elevadas, sendo reduzidas a medida que as secagens são processadas.

O modelo matemático de Page foi o que melhor se ajustou aos dados experimentais de cinética de secagem das sementes de pitaya vermelha, apresentando coeficientes de determinação $\left(\mathrm{R}^{2}\right)$ superiores a 0,99 , desvios quadráticos médios (DMQ) inferiores a 0,030 e distribuição aleatória dos resíduos, podendo ser utilizado satisfatoriamente para representar o fenômeno investigado.

\section{Agradecimentos}

A Coordenação de Aperfeiçoamento de Pessoal de Nível Superior (CAPES) pelo apoio financeiro indispensável na execução do presente trabalho.

\section{Referências}

Abreu, W. C., Lopes, C. O., Pinto, K. M., Oliveira, L. M., Carvalho, G. B. M., \& Barcelos, M. F. P. (2012). Características físico-químicas e atividade antioxidante total de pitaias vermelha e branca. Revista do Instituto Adolfo Lutz, (71)4, 656-661.

Ariffin, A. A., Bakar, J., Tan, C. P., Rahman, R. A., Karim, R.; \& Loi, C. C. (2009). Essential fatty acids of pitaya (Dragon fruit) seed oil. Food Chemistry, 114(1), 561-564. http://dx.doi.org/10.1016/j.foodchem.2008.09.108

Borges, S. V., Mancini, M. C., Corrêa, J. L. G., \& Leite, J. (2010). Secagem de bananas prata e d'água por convecção forçada. Ciência e Tecnologia de Alimentos, 30(3), 605-612. http://dx.doi.org/10.1590/S0101-20612010000300006.

Carlesso, V. O., Berbert, P. A., \& Silva, R. F. (2007). Detmann, E. Avaliação de modelos de secagem em camada fina de sementes de maracujá amarelo. Revista Brasileira de Sementes, 29(2), 28-37. http://dx.doi.org/10.1590/S0101-31222007000200005.

Chayjan, R. A., Agha-alizade, H. H., Barikloo, H., \& Soleymani, B. (2012). Modeling some drying characteristics of cantaloupe slices. Cercetări Agronomice in Moldova, 45(2), 5-14. http://dx.doi.org/10.2478/v10298-012-0009-6 
Corrêa, P. C., Resende, O., Martinazzo, A. P., Goneli, A. L. D., \& Botelho, F. M. (2007). Modelagem matemática para a descrição do processo de secagem do feijão (Phaseolus vulgaris L.) em camadas delgadas. Revista Engenharia Agrícola, 27(2), 501-510. http://dx.doi.org/10.1590/S0100-69162007000300020.

Deamici, K. M., Oliveira, L. C., Rosa, G. S., \& Oliveira, E. G. (2016) Drying kinetics of fermented grape pomace: Determination of moisture effective diffusivity. Revista Brasileira de Engenharia Agrícola e Ambiental, 20(8), 763-768. http://dx.doi.org/10.1590/1807-1929/agriambi.v20n8p763-768

Diógenes, A. M. G., Queiroz, A. J. M., Figueirêdo, R. M. F., \& Santos, D. C. (2013). Cinética de secagem de grãos de abóbora. Revista Caatinga, 26(1) 71-80.

Ferreira, L. F. D., Pirozi, M. R., Ramos, A. M., \& Pereira, J. A. M. (2012). Modelagem matemática da secagem em camada delgada de bagaço de uva fermentado. Pesquisa Agropecuária Brasileira, 47(6), 855-862. http://dx.doi.org/10.1590/S0100-204X2012000600017

Galdino, P. O., Figueirêdo, R. M. F., Queiroz, A. J. M., \& Galdino, P. O. (2016). Drying kinetics of atemoya pulp. Revista Brasileira de Engenharia Agrícola e Ambiental, 20(7), 672-677, http://dx.doi.org/10.1590/1807-1929/agriambi.v20n7p672-677

Guimarães, M. K. A., Queiroz, A. J. M., \& Figueirêdo, R. M. F. (2017). Foam-mat drying kinetics of keitt mango pulp. Revista Caatinga, 30(1), 172-180. http://dx.doi.org/10.1590/1983-21252017v30n119rc

Liaotrakoon, W., DE Clercq, N., Van hoed, V., \& Dewettinck, K. (2013). Dragon fruit (Hylocereus spp.) seed oils: their characterization and stability under storage conditions. Journal of the American Society Oil Chemists, 90(2), 207-215. http://dx.doi.org/10.1007/s11746-012-2151-6

Lima, C. A., Faleiro, F. G., Junqueira, N. T. V., Cohen, K. O., \& Guimarães, T. G. (2013). Características físico-químicas, polifenóis e flavonoides amarelos em frutos de espécies de pitaias comerciais e nativas do Cerrado. Revista Brasileira de Fruticultura, 35(2), 565-570. http://dx.doi.org/10.1590/S010029452013000200027

Lima, C. A., Faleiro, F. G., Junqueira, N. T. V., \& Bellon, G. (2014). Avaliação de características físico-químicas de frutos de duas espécies de pitaya. Revista Ceres, 61(3), 377-383. http://dx.doi.org/10.1590/S0034-737X2014000300012

Martins, J. J. A., Marques, J. I., Santos, D. C., \& Rocha, A. P. T. (2014). Modelagem matemática da secagem de cascas de mulungu. Bioscience Journal, 30(6), $1652-1660$.

Mandala, I. G., Anagnostaras, E. F., \& Oikonomou, C. K. (2005). Influence of osmotic dehydration conditions on Apple air-drying kinetics and their quality characteristics. Journal Food Engineering, 69(3), 307-316. http://dx.doi.org/10.1016/j.jfoodeng.2004.08.021

Massamba, D., Matouba, E., Elenga, G., Maniongui, J. G., \& Silou, T. (2012). Mathematical modelling of microwave drying of safou pulp. Pakistan Journal of Nutrition, 11(6), 553-560. http://dx.doi.org/10.3923/pjn.2012.553.560

Mendonça, A. P., Sampaio, P. T. B., Almeida, F. A. C., Ferreira, R. F., \& Novais, J. M. (2015). Determinação das curvas de secagem das sementes de andiroba em secador solar. Revista Brasileira de Engenharia Agrícola e Ambiental, 19(4), 382-387. http://dx.doi.org/10.1590/1807-1929/agriambi.v19n4p382-387

Rabha, D. K., MuthukumaR, P., \& Somayaji, C. (2017). Experimental investigation of thin layer drying kinetics of ghost chilli pepper (Capsicum Chinense Jacq.) dried in a forced convection solar tunnel dryer. Renewable Energy, 105(1), 583-589. http://dx.doi.org/10.1016/j.renene.2016.12.091

Roberts, J. S., Kidd. D. R., \& Padilha-zakour, O. (2013). Drying kinetics of grape seeds. Journal of Food Engineering, 89(4), 460-465. http://dx.doi.org/10.1016/j.jfoodeng.2008.05.030

Santos, D. C., Queiroz, A. J. M., Figueirêdo, R. M. F., \& Oliveira, E. N. A. (2013a). Cinética de secagem de farinha de grãos residuais de urucum. Revista Brasileira de Engenharia Agrícola e Ambiental, 17(2), 223-231. http://dx.doi.org/10.1590/S1415-43662013000200014

Santos, D. C., Queiroz, A. J. M., Figueirêdo, R. M. F., \& Oliveira, E. N. A. (2013b). Mathematical modeling for the annatto (Bixa orellana L.) seed drying process. Chilean Journal of Agricultural Research, 73(3), 320-326. http://dx.doi.org/10.4067/S0718-58392013000300017

Santos, D. C., QueiroZ, A. J. M., Figueirêdo, R. M. F., \& Oliveira, E. N. A. (2014). Drying of residual grains of annatto in a heat accumulator dryer combined with drying in a solar dryer. Boletim do Centro de Pesquisa de Processamento de Alimentos, 32(2), 305-318. http://dx.doi.org/10.5380/cep.v32i2.39074

Santos, D. C., Queiroz, A. J. M., Figueirêdo, R. M. F., \& Oliveira, E. N. A. (2015). Sun drying of residual annatto seed powder. Acta Scientiarum. Technology, Maringá, 37(1), 161-166, 2015. http://dx.doi.org/10.4025/actascitechnol.v37i1.20582

Sousa, K. A., Resende, O., ChaveS, T. H., \& Costa, L. M. (2011). Cinética de secagem do nabo forrageiro (Raphanus sativus L.). Revista Ciência Agronômica, 42(4), 883-892.

Taheri-garavand, A., Rafiee, S., \& Keyhani A. (2011). Effective moisture diffusivity and activation energy of tomato in thin layer dryer during hot air drying. International Transaction Journal of Engineering, Management, \& Applied Sciences \& Technologies, 2(2), $239-248$. 